\title{
Trabalho no Nordeste em perspectiva histórica ${ }^{1}$
} ROBERTO VÉRAS DE OLIVEIRA ${ }^{I}$

\section{Introdução}

$\mathrm{E}$ STE ENSAIO tem como propósito identificar e analisar, em perspectiva histórica, as dinâmicas sociais do trabalho que se estabeleceram no Nordeste, especialmente em relação à reconfiguração socioeconômica da região empreendida a partir da criação da Superintendência do Desenvolvimento do Nordeste (Sudene), no final dos anos 1950. Motivado pela retomada na última década de uma agenda de grandes projetos público-privados no país e na região, busca-se sob um olhar retrospectivo reconstituir fios interpretativos que possam contribuir para adensar o entendimento do momento atual e de suas possibilidades de desdobramentos.

Seguindo uma tradição de estudos que associam trabalho e desenvolvimento, ${ }^{2}$ objetivamos explorar as implicações recíprocas entre as transformações socioeconômicas suscitadas por impulsos e padrões diversos de desenvolvimento e as dinâmicas sociais do trabalho estabelecidas em cada um dos principais momentos do processo histórico recente da região.

Partimos do pressuposto de que, nas sociedades modernas, não podemos senão falar de padrões de desenvolvimento sob o capitalismo. Concebemos ideias e situações que se coloquem para além e, mesmo, como contraponto à estrita lógica da acumulação de capital, mas não que a ignorem. Com Harvey (1992) e a Escola da Regulação, admitimos que o desenvolvimento capitalista comporta regimes de acumulação e modos de regulação distintos, em contextos temporal e espacialmente diversos.

De Boltanski e Chiapello (2009, p.35) incorporamos a percepção do capitalismo em associação com a "exigência de acumulação ilimitada do capital por meios formalmente pacíficos" (uma contínua e cumulativa reposição, no circuito econômico, do lucro obtido com as inversões de capital) e com o trabalho assalariado (sustentado, de um lado, na existência de uma parcela majoritária da população que, destituída de capital, necessita vender sua força de trabalho ao capitalista, e, de outro, em um fundamento jurídico que garanta o caráter contratual dessa relação mercantil). A inserção de capitalistas (e trabalhadores) nesse processo requer justificações morais, visando evidenciar "as vantagens coletivas, definidas em termos de bem comum, com que ela contribui para todos": "chamamos de espírito do capitalismo a ideologia que justifica o engajamento no capitalismo" (Boltanski; Chiapello, 2009, p.39). 
Os referidos autores identificam dois níveis de crítica ao capitalismo. Um, "primário", que se refere à esfera das emoções e da indignação, estando sempre pronto a brotar impulsivamente. O outro, "secundário", tem caráter reflexivo e argumentativo, sendo capaz de dar sustentação à luta ideológica. Como principais tipos de críticas na história do capitalismo, destacam: sua associação com o desencanto e a inautenticidade; seu caráter de opressão; sua capacidade de gerar miséria para os trabalhadores e desigualdades sociais; e de inspirar oportunismo e egoísmo. Propõem, com isso, uma concepção não determinista do social. O processo de desenvolvimento capitalista se faz em um jogo dialético entre a crítica e a justificação, e um dos principais espaços nos quais essa dinâmica se estabelece se refere ao mundo do trabalho.

Assim inspirados, tomamos o trabalho como fonte de questionamentos prático-discursivos e alvo de justificações, que testam e alimentam a dinâmica capitalista: nas hibridizações e contrapontos entre as formas salariais e não salariais de relações de trabalho; na possibilidade de as formas disponíveis de trabalho gerarem produção e renda, assim como suscitarem realizações socioprofissionais e insatisfações; na diversidade de modos de resistência e de luta conflagrada, especialmente entre trabalhadores e capitalistas; nos processos de constituição de agências de elaboração prático-discursiva, demarcadas por disputas entre si e por oposições de classe (com destaque para as organizações sindicais).

Neste texto, abordamos as conexões que historicamente vêm se estabelecendo entre as dinâmicas sociais do trabalho e as políticas de desenvolvimento, no espaço nordestino. Para tanto, lançamos mão de estudos referidos ao tema, de informações estatísticas e do suporte de pesquisas próprias. Começamos desenvolvendo uma breve contextualização da reestruturação da economia nordestina a partir da intervenção da Sudene, realçando o processo de integração produtiva com o Centro-Sul e suas implicações diferenciadoras no plano interno. Na sequência, centrando no período áureo da Sudene, detemo-nos sobre a via nordestina de "modernização" das relações de trabalho, concluindo com um destaque para o caso do Polo Petroquímico de Camaçari. A seguir, com um foco nos anos 1990 e na emergência do fenômeno da "guerra fiscal", analisamos seus desdobramentos para as dinâmicas do trabalho, finalizando com o caso do Polo Têxtil-Calçadista de Fortaleza. Na parte seguinte, analisamos as mudanças trazidas com a retomada das políticas de desenvolvimento no país e na região, nos anos 2000, finalizando com o Complexo Industrial Portuário de Suape. Concluímos com algumas considerações finais.

\section{A questão regional e a Sudene: uma perspectiva de desenvolvimento}

As características contemporâneas das dinâmicas sociais do trabalho no contexto nordestino têm suas raízes na formação sócio-histórica da região e, sobretudo, nas transformações trazidas com a Sudene. Nas décadas de 1990 e seguintes, reconfigurações foram se estabelecendo a partir de, e modificando, tal base. 
Guimarães Neto (1997) identifica três fases principais na história econômica nordestina: da colonização à metade do século XIX, quando se constituiu um complexo econômico com base na produção para exportação de cana-de-açúcar (e, em seguida, algodão, fumo, cacau etc.), lastreada no trabalho escravo e complementada com a pecuária extensiva e a agricultura de subsistência; de fins do século XIX à metade do seguinte, com o complexo regional passando a se articular comercialmente com outros espaços regionais, formando o mercado interno brasileiro, entretanto com crescente perda de espaço, fora e internamente, para os produtos do Centro-Sul (cada vez mais voltado à industrialização); ${ }^{3}$ do final dos anos 1950 em diante, quando, como solução para a "questão regional", produto da crescente discrepância da economia nordestina diante da pujança industrial do eixo São Paulo-Rio, teve início o processo de "transferência para as regiões periféricas, inclusive o Nordeste, de frações do capital produtivo, público e privado, que, explorando novas oportunidades de investimento nesses espaços, promoveriam uma integração produtiva dessas regiões, já articuladas comercialmente desde a fase anterior" (Guimarães Neto, 1997, p.40).

Com Celso Furtado à frente, em 1957, foi criado o Grupo de Trabalho de Desenvolvimento do Nordeste (GTDN), ao qual coube realizar um diagnóstico sobre os entraves ao desenvolvimento da região e propor ações para sua superação. Dentre essas se destacaram: industrialização, reestruturação agrícola, colonização, investimento em energia etc. (Grupo de Trabalho de Desenvolvimento do Nordeste, 1967). Daí se originou a Sudene, em 1959.

Com o Banco do Nordeste do Brasil (BNB) (criado em 1952), estabeleceram-se as bases de uma política desenvolvimentista para o Nordeste. Para Oliveira (1981), até o golpe militar, enquanto o conflito de classes não se definia, houve alguma disputa sobre o projeto da Sudene, envolvendo a burguesia internacional-associada do Centro-Sul, a burguesia industrial nordestina, a oligarquia agrária algodoeiro-pecuária e as forças populares. Antes, entretanto, observa o autor, a inclusão no Primeiro Plano Diretor da opção de dedução do imposto de renda das empresas como medida de incentivo aos investimentos industriais no Nordeste, sendo proporcional ao porte de cada uma, favoreceu a expansão monopolista.

Teve início a Era Sudene. Segundo Araújo (2002), a partir da década de 1960, por meio de incentivos fiscais, de investimentos de empresas estatais (com destaque para a Petrobras e a Vale do Rio Doce) e de créditos públicos (do BNDES e do $\mathrm{BNB}$, principalmente), o eixo da indústria da região se deslocou da produção de bens de consumo não duráveis (têxteis, calçados, vestuário, alimentos) para a produção de bens intermediários. Nesse contexto, ganharam destaque o Polo Petroquímico de Camaçari, sediado na Bahia, e o Complexo Minerometalúrgico, no Maranhão. Houve modernização também de espaços agrícolas (áreas de irrigação) e dos serviços urbanos (regiões metropolitanas), embora no Semiárido tenha persistido a agricultura de subsistência e a pecuária 
extensiva e, nas cidades, tenha crescido uma economia de base informal (Guimarães Neto, 1997). Entre 1967 e 1989, enquanto a indústria elevou seu peso no PIB regional de 22,6\% para 29,3\%, e o setor de serviços, de 49,9\% para 58,6\%, a agropecuária encolheu de 27,4\% para 18,9\% (Araújo, 2002).

No conjunto, a economia regional acompanhou o desempenho da economia brasileira, entre 1960 e 1993, ora acima, ora abaixo. Segundo Gomes e Vergolino (1995), de 1960 a 1967, o Nordeste cresceu mais do que o Brasil, com taxas médias anuais de 4,4\% e 3,9\%, respectivamente. Entre 1968 e 1973, no "Milagre Brasileiro", a situação se inverteu, com taxas, correspondentes, de 7,2\% e 10,9\%. No período do "choque do petróleo", de 1974 a 1980, ocorre nova inversão, com 7,4\% para o Nordeste e 6,8\% para o Brasil. Nos anos de "crise da dívida", de 1981 a 1983, as taxas foram, na mesma ordem, de 2,6\% e -2,2\%. De 1984 a 1986 (com a economia em recuperação), o Nordeste segue crescendo mais, com 10,1\%, e o Brasil, 7,0\%. Finalmente, de 1987 a 1993 (estagnação econômica e elevada inflação), a região volta a crescer menos, com $-0,5 \%$ e $0,5 \%$, respectivamente. Entre 1960 e 1993, as taxas médias de crescimento anual se mantiveram próximas: $5,5 \%$ no Nordeste e 5,6\% no Brasil.

Segundo Oliveira (1981) e Araújo (2002), o resultado desse processo foi a integração dependente, com a expansão industrial do Nordeste, de 1960 a 1980 , baseando-se em investimentos de capitais do Centro-Sul. Na nova divisão regional do trabalho, coube à região o papel produtor de insumos para a indústria do Sudeste.

No novo espaço econômico nordestino, Gomes e Vergolino (1995) identificam a formação de quatro sub-regiões principais: as áreas metropolitanas de Salvador, Recife e Fortaleza, onde se concentrou a maior parte dos grandes projetos industriais (o polo têxtil e de confecções do Ceará, as indústrias de fiação e tecelagem, metalmecânica, química, papel e celulose, em Pernambuco, o Polo Petroquímico de Camaçari, na Bahia), tendo em conjunto passado, de 1970 a 1992, de 26,4\% para 46,7\% do Produto Interno Bruto (PIB) da região; a zona da Mata, incluindo a costa oriental e quase todo o Maranhão, com destaque para a agroindústria sucroalcooleira, o cacau, na Bahia, e o babaçu e madeira, no Maranhão, além do turismo e uma base industrial e de serviços, nas capitais não metropolitanas; o Semiárido, onde historicamente se concentrou uma economia de baixa produtividade, baseada na pecuária extensiva e na agricultura de subsistência, contando ainda com o agravante das secas cíclicas, tendo peso no PIB regional caído de 43,18\%, em 1970, para 31,5\%, em 1988; os principais polos de irrigação, com a emergência de uma agroindústria moderna, com destaque para a área do Açu, no Rio Grande do Norte, de Corredeiras do São Francisco e dos Cerrados, na Bahia, e do Sertão do São Francisco, em Pernambuco, com foco no mercado extrarregional.

Os investimentos se concentraram em grandes projetos industriais, agrícolas ou de serviços, a partir dos quais se constituíram os vínculos da economia 
regional com os capitais e mercados extrarregionais, com as áreas dinâmicas passando a coexistir com grandes sub-regiões estagnadas (Guimarães Neto, 1997). Em geral, resultaram de associações entre Estado e capitais privados local, nacional e internacional. Conforme evidenciou Araújo, Souza e Lima (1997), tais "polos" foram constituídos se diferenciando das atividades tradicionais, entretanto mantendo uma capacidade de irradiação limitada, ${ }^{4}$ sob restrito acesso à terra e aos fundos públicos. No novo arranjo, novos contrastes, desequilíbrios, desigualdades foram produzidos, com a pobreza perseverando: "No Nordeste, o crescimento econômico fez triplicar o PIB (de US\$20,8 bilhões em 1970 atingiu US\$ 65,3 bilhões em 1993, medidos a preços de 1993 pela Sudene), enquanto o produto per capita apenas duplicou no mesmo período (passou de US\$ 740 para US\$ 1.486)" (Araújo, 2002, p.30).

\section{A Sudene e a via nordestina}

\section{de "modernização" das relações de trabalho}

As transformações socioeconômicas empreendidas no Nordeste, sob o guarda-chuva da Sudene, impactaram fortemente nos padrões de relações de trabalho. Entretanto, as heranças do trabalho escravo e da estrutura fundiária baseada no latifúndio, associadas ao longo processo de incorporação do trabalho assalariado e à grande disponibilidade de mão de obra, entre outros aspectos, condicionaram a manutenção, mesmo com os novos projetos, de relações espoliativas de trabalho e de baixos níveis de remuneração (Guimarães Neto, 1997).

Ao priorizar investimentos em setores intensivos em capital, a Sudene contribuiu para a constituição de um segmento destacado e reduzido de trabalhadores relativamente qualificados e bem remunerados (Oliveira, 2003a). No conjunto, segundo Araújo (2002), houve uma expansão do assalariamento na região, atingindo prioritariamente as zonas urbanas (com a expansão da indústria e dos serviços), mas também as zonas rurais (tanto as antigas, a exemplo da cana-de-açúcar, como as novas regiões de investimento agroindustrial).

Quanto ao setor público, que sempre desempenhou importante papel na determinação no emprego e na geração de demanda, teve importante crescimento até meados da década de 1980, quando começou a declinar (Gomes; Vergolino, 1995, p.67-70). Alterações de perfil socioprofissional também teriam acontecido nas classes médias (por exemplo, com a queda no nível de remuneração dos funcionários públicos e com a emergência de profissionais da informática, do marketing, da administração de empresas estatais e privadas etc.). Surgiram novas gerações de empresários industriais e de serviços, inclusive oriundas das velhas oligarquias (Araújo, 2002).

Para os que não conseguiam se alocar nas velhas e novas oportunidades de trabalho assalariado, colocavam-se as "opções" do autoemprego ou da migração. E, muitas vezes, uma redundava na outra. $\mathrm{O}$ trabalho autônomo, informal, não só continuou sendo um refúgio ao desemprego nas áreas urbanas nordestinas, como foi intensificado nesse novo processo de industrialização da região. 
Quanto à migração, Araújo (2002, p.33) comenta: "entre 1960 e 1980, estima-se que deixaram a região cerca de quatro milhões de nordestinos". Com isso, dinâmicas tradicionais permaneceram ao mesmo tempo em que novos atores sociais emergiram (Carvalho, 1989), sob um contexto socioeconômico marcado por discrepâncias de renda e de formas de inserção produtiva.

A Bahia foi a maior beneficiada dos incentivos da Sudene. Até o início dos anos 1950, pesava sobre esse Estado o domínio de uma oligarquia agrário-financeira, quando começou uma profunda transformação, trazida com a instalação da refinaria de Mataripe da Petrobras (depois Landulpho Alves). A construção do Centro Industrial de Aratu preparou as bases para a implantação, nos anos 1970, do Complexo de Camaçari, sustentado em capitais estatais e privados nacionais e multinacionais. Com isso, o perfil do emprego na Região Metropolitana de Salvador mudou radicalmente, entre 1940 e 1970: na agricultura, caiu de $23,6 \%$ para $5,7 \%$ da PEA; na indústria, passou de $16,5 \%$ a $26,1 \%$; no terciário, também cresceu de $59,9 \%$ para $68,2 \%$. No período, as taxas de crescimento anual do emprego foram de $-0,96 \%$ na agricultura, $5,4 \%$ na indústria e $4,3 \%$ no terciário. Uma nova dinâmica concentracionista de renda se estabeleceu, sendo também segmentadora quanto ao perfil dos trabalhadores, com clivagens salariais, de gênero, de geração, de qualificação (Oliveira, 2003a).

Em estudo publicado originalmente em 1987, Oliveira (2003a) avalia as implicações de tais transformações para as classes e suas representações. Surgiram as novas "classes médias", com a incorporação, na nova base socioeconômica, de técnicos, engenheiros, químicos, gerentes, administradores, planejadores etc. Politicamente, sua importância derivava da condição de mediadora na relação entre capital, salário e fundo público, resultando em uma "super-representação". Sobre os trabalhadores assalariados, uma combinação entre uma imensa oferta de mão de obra ("exército industrial de reserva"), a incorporação de uma matriz técnica intensiva em capital e que "des-especializa" (com um processo de trabalho baseado na montagem), associadas a uma dinâmica que leva à hierarquização e à segmentação nas relações de trabalho, resultou em: elevada rotatividade da mão de obra, baixos salários, vínculos precários, forte concorrência entre os trabalhadores e entraves para a afirmação de uma identidade de classe. De outra parte, desenvolveu-se ainda mais um conjunto não homogêneo de atividades não capitalistas. $\mathrm{O}$ assim denominado "setor informal" pela literatura da época já havia sido analisado por Oliveira (2003b): longe de significar uma realidade desarticulada, constituiu-se em uma relação dialética com o processo de acumulação que informou a tardia industrialização brasileira. Fez-se na base do uso intensivo de mão de obra, concentrando-se no comércio ambulante, serviços pessoais, serviços de reparação, entre outros.

Naquele contexto, as possibilidades de reação política por parte dos trabalhadores foram avaliadas por Oliveira (2003a) como "uma quase-impossibilidade", ao se associarem: baixa tradição de organização sindical, uma matriz técnico-social produtora de segmentação e hierarquização entre os trabalhado- 
res e a repressão política patrocinada pelo Regime Militar. Para Druck (1999), os empresários se viam autorizados para implementarem processos de intensa racionalização do trabalho, nos termos do que Alain Lipietz (1988) denominou “fordismo periférico". Resultava dali uma certa homogeneização fordista dos trabalhadores do Polo, ao mesmo tempo que contribuía para aprofundar a heterogeneidade do mercado de trabalho, ao demarcar grandes distâncias entre eles e, deles, para com os outros, situados fora do Polo.

Contudo, os novos ares da política brasileira da passagem dos anos 1970 aos 1980, tendo nas lutas operárias do ABC Paulista e no "novo sindicalismo" que daí derivou uma de suas principais expressões, ${ }^{5}$ repercutiu no novo segmento da classe trabalhadora baiana, com destaque para os operários do Complexo de Camaçari. Conforme Druck (1999, p.176): “A revitalização do movimento sindical, sua politização e suas práticas de luta e resistência - conquistando algumas vitórias pontuais, mas importantes - foi um processo que tornou mais visível o surgimento de uma classe operária moderna”. Também Castro e Guimarães (1995) evidenciam que apesar da ausência de uma cultura operária na região e da origem social desses trabalhadores em setores da classe média, as aspirações dos novos operários haviam esbarrado nos limites da carreira fabril e no caráter autoritário da cultura gerencial, ${ }^{6}$ favorecendo a emergência de um discurso antipatronal, “classista”, com manifestas expressões de solidariedade frente às demandas dos demais trabalhadores.

Um novo capítulo, no entanto, abre-se no Complexo e no Nordeste, com as novas estratégias empresariais e políticas governamentais incorporadas nos anos 1990 .

\section{A crise do Estado "planejador",}

\section{a "guerra fiscal" e as novas formas do trabalho precário}

Nos anos 1990, uma associação entre políticas econômicas de viés neoliberal e uma intensificação dos processos de reestruturação produtiva, responsáveis pela incorporação de inovações tecnológicas e gerenciais, produziram uma generalizada crise do emprego em todo o país, "com crescente elevação do desemprego aberto e das ocupações não-assalariadas. Em contrapartida, houve o decréscimo do assalariamento, especialmente daquele com carteira assinada, em relação ao total da ocupação" (Pochmann, 2008, p.59).

Essas transformações seguiram uma tendência global. Para Harvey (1992), com a "acumulação flexível", produziu-se uma crescente segmentação nas relações de trabalho. Aos empregados regulares (em proporção decrescente) impôs-se a flexibilização das funções e da jornada de trabalho. Em contraste, cresceram os tipos de trabalho periféricos (emprego em tempo integral com baixa qualificação, parcial, temporário, subcontratado), revivendo sistemas antigos (trabalho doméstico, artesanal, familiar, paternalista).

Sobre a América Latina, a flexibilização das relações de trabalho, como notou Toledo (1997), não pode ser compreendida sem considerar o papel exercido 
pelo Estado. A adesão ao neoliberalismo foi, quanto a isso, essencial. Quanto ao Brasil, segundo Castro e Leite (1994), Antunes (1997), entre outros, se na década de 1980 foi possível observarem-se algumas inovações tecnológicas e organizacionais no parque industrial brasileiro, somente a partir de 1990 tal processo se intensificou, com a adoção no país de medidas de liberalização e privatização da economia.

Esse quadro repercutiu ainda mais fortemente no Nordeste, visto que a participação do Estado na economia, direta (investimentos em infraestrutura e empresas estatais) e indiretamente (incentivos ao capital privado, geração de demanda, geração de emprego), passou, com as políticas da Sudene, a ter um peso ainda mais decisivo. Para Gomes e Vergolino (1995), deve-se ressaltar o fato de que o encolhimento do governo ocorreu, na região, de modo mais rápido, em comparação com o resto do país. A Sudene e as políticas de desenvolvimento regional sofreram crescente desgaste, até sua extinção em 2001. No seu lugar foi criada, com funções mais modestas, a Agência de Desenvolvimento do Nordeste (Adene).

Araújo, Souza e Lima (1997), com base em dados do IBGE, evidenciaram que as taxas de desemprego das Regiões Metropolitanas de Recife e Salvador permaneceram, de 1982 a 1994, em patamares bem acima dos verificados para as demais Regiões Metropolitanas (RM) (Belo Horizonte, Rio de Janeiro, São Paulo, Porto Alegre). Enquanto no Sudeste cerca de $44 \%$ da população ocupada não contribuíam para a Previdência Social, no Nordeste essa proporção era de $75,8 \%$. O percentual de empregados com carteira assinada sobre o conjunto da população ocupada foi, para o Sudeste, de 40\%, e, para o Nordeste, de 15,6\%. A informalidade na economia nordestina se encontrava em patamar bem acima do verificado para as regiões mais desenvolvidas do país.

Nas áreas industriais mais dinâmicas da região, os impactos no trabalho foram contundentes. No Polo de Camaçari, as privatizações, uma maior internacionalização e a incorporação de novos padrões tecnológicos e de gestão desencadearam, desde o início da década, intensa reestruturação empresarial, com fusões e aquisições, extinção de setores, cargos e níveis de chefia e gerências, com a incorporação de formas de terceirização e do modelo da qualidade total (Druck, 1999). Como resultado, veio o desemprego - com o Polo chegando a atingir um nível de emprego correspondente a "cerca de $1 / 3$ do máximo alcançado nos anos de 1980" (Almeida, 2008, p.42).

Em um contexto de elevado desemprego, para muitos restaram as tradicionais "opções" do autoemprego e da migração. Embora o trabalho autônomo quase sempre implique precariedade (baixa remuneração, instabilidade, falta de proteção social), uma economia pujante pode florescer de iniciativas como essas. Foi o caso do Polo de Confecções do Agreste de Pernambuco, ${ }^{7}$ que se estabeleceu como um aglomerado produtivo e comercial do setor de confecções, a partir dos anos 1950/1960, com as "Feiras da Sulanca", em Santa Cruz do Capibaribe, Caruaru e Toritama. Desenvolveu-se lentamente, até que, 
a partir do final dos anos 1990, passou a incorporar novas estruturas comerciais e um processo de modernização produtiva e institucional, ganhando a nova denominação de "Polo", em lugar de "Feira da Sulanca". Destaque-se que tal aglomerado produtivo não resultou dos incentivos da Sudene, nem da "guerra fiscal", ao contrário foi sendo gestado com base no trabalho familiar, domiciliar e informal. Estimativas de Raposo e Gomes (2003) indicavam, no começo dos anos 2000, a existência de 12 mil unidades produtivas, ${ }^{8}$ dentre as quais apenas $8 \%$ formalizadas. Ao todo empregavam, direta e indiretamente, por volta de 76 mil pessoas e produziam 57 milhões de peças por mês.

Considerando-se a elevada concentração da estrutura produtiva regional nas RM de Salvador, Recife e Fortaleza, estas, segundo avaliou Fusco (2012, p.102), mesmo não tendo apresentado bom desempenho econômico na década de 1990, "contribuíram para reter muitos migrantes que, do contrário, teriam seguido a tradição de se deslocar para os centros mais dinâmicos da economia nacional". Isso, em um contexto de aumento no fluxo migratório na região em razão das grandes secas que assolaram o semiárido entre 1990-1993 e 1998-1999.

Uma frente de novos investimentos veio com o incremento da indústria do turismo. Para Dantas e Silva (2009), os estados mais favorecidos entre 1995 e 2003 foram Bahia e Ceará, juntos reunindo 51\% dos recursos. Mas os rendimentos do trabalho gerados no setor situaram-se na média em níveis bem baixos, com apenas $6,1 \%$ dos ocupados na faixa de cinco ou mais salários mínimos, e $6,3 \%$ na faixa de três a cinco salários mínimos.

As mudanças mais importantes vieram, no entanto, com os novos investimentos no setor de vestuário, principalmente no Ceará. ${ }^{9}$ Segundo Saboia (2001), a associação entre a reestruturação produtiva (que atingiu, sobretudo, as regiões industriais mais dinâmicas do país, produzindo desemprego e precarização do trabalho) e a implementação da "guerra fiscal"10 (que envolveu estados e municípios na disputa por "novos investimentos") teve como uma de suas consequências o deslocamento de plantas industriais do Centro-Sul para o Nordeste. J. Lima (2002) destacou que, para as populações locais - condicionadas historicamente a escassas oportunidades de emprego e baixo padrão de remuneração -, os novos investimentos representaram oportunidades antes não existentes.

O setor de vestuário, não obstante as inovações tecnológicas, continuava intensivo em mão de obra. Diante da crescente concorrência internacional, os processos de reestruturação produtiva visaram o incremento da subcontratação e o deslocamento das plantas industriais para regiões com menores custos de produção, sobretudo com mão de obra barata, baixa tradição de regulação dos mercados e ausência de organização sindical. Foi o que ocorreu com a indústria têxtil/confecções e calçadista de São Paulo e do Sul, gerando o deslocamento de plantas industriais para o Nordeste, sendo a "guerra fiscal" seu instrumento e o Ceará, seu principal destino. 
O Ceará havia sido um dos principais beneficiados com as políticas da Sudene. Segundo P. Lima (1994), entre 1963 e 1990, a Bahia teria barganhado $29,4 \%$ dos recursos daquele órgão, Pernambuco, 17,5\%, e Ceará, 16,0\%. Nesse último caso, o foco recaiu sobre os setores têxtil e de vestuário. No conjunto da produção regional, a indústria têxtil havia perdido importância com as políticas desenvolvimentistas e a crise na produção regional de algodão. Mas, tendo passado por intenso processo de modernização, seu eixo mais dinâmico foi deslocado da RM de Recife para a RM de Fortaleza: "Em 1991, segundo o Sindicato da Indústria de Confecções do Ceará, o polo cearense reunia cerca de 3.000 empresas, gerava 60.000 empregos diretos e era responsável por 12\% do ICMS do Ceará” (P. Lima, 1994, p.67).

Desde 1986, visando os setores que se encontravam sob impacto da concorrência internacional, o governo estadual se lançou em uma ofensiva para convencer empresas do Centro-Sul das vantagens de investirem no Ceará: "infra-estrutura, prédios, isenção fiscal, mão-de-obra abundante, treinamento e qualificação de trabalhadores, baixa organização sindical desses trabalhadores e a possibilidade de terceirização da produção em cooperativas" (J. Lima, 2002, p.52). A prioridade era atrair as cadeias produtivas têxtil/confecções e de calçados. Com os novos investimentos, de acordo com Dantas e Silva (2009), a participação dos setores de fiação, tecelagem e calçadista no PIB do Ceará passou, de 1970 para 1997 , de $18,6 \%$ para $27,4 \%$.

Um diferencial da iniciativa cearense, naquela ocasião, foi a oferta da possibilidade da subcontratação via cooperativas de produção, incentivadas pelo governo, as quais visavam garantir mão de obra ainda mais barata, ao eliminar custos com encargos trabalhistas. Ao Estado caberia: a construção de galpões para serem cedidos às cooperativas, mas permanecendo como propriedade do Estado; a articulação das parcerias, responsáveis pelo fornecimento da matéria-prima e pela compra do produto, sendo garantia de mercado; a arregimentação e qualificação da mão de obra; o acompanhamento técnico do processo de organização das cooperativas. Quanto às empresas que aceitassem ser parceiras caberia a "função de prover os dois elos que faltavam nas atividades produtivas de pequeno porte: a tecnologia - o aperfeiçoamento dos produtos e processos e o acesso ao mercado" (J. Lima, 2002, p.56). As cooperativas, induzidas pelo Estado e em sua maioria constituídas por mulheres, deveriam ser a principal base de constituição dos minidistritos industriais situados no interior do estado. Em troca da geração de emprego e renda a iniciativa governamental se dispôs a favorecer a flexibilização da legislação trabalhista.

Influenciado pelo modelo cearense, tal estratégia foi implementada também no setor e calçados, envolvendo com destaque, além do Ceará, os estados da Paraíba, do Rio Grande do Norte e de Pernambuco. De um ponto de vista conclusivo, J. Lima (2002, p.109) observa: 
No Nordeste, o novo proletariado é formado por trabalhadores que circulam entre cooperativas e unidades industriais, em suas distintas formas - unidades fabris, empresas terceirizadas, cooperativas - tem significado a inclusão de partes da população, que vivia numa economia de subsistência, à produção capitalista e ao consumo, a partir de ganhos monetários relativamente regulares. Todavia, a inclusão insere-se num contexto de flexibilização da produção e das relações de trabalho, o que resulta em formas precarizadas de assalariamento - com direitos restritos ou sem direito algum.

Em áreas com concentrações de cooperativas, como o que se estabeleceu no município de Araripe e entorno, houve um princípio de organização das trabalhadoras, com o apoio da Pastoral Operária da Igreja Católica, com a empresas sendo acionadas na Justiça do Trabalho. Vários foram os casos que, como esse, tiveram a interdição da Justiça como desfecho (ibidem).

\section{A retomada dos grandes projetos e as perspectivas do trabalho}

O governo Lula inaugurou um período de recuperação econômica, com repercussões positivas sobre o trabalho. Mesmo com a crise global de 2008 e seus efeitos sobre o PIB, ${ }^{11}$ o mercado de trabalho mantém-se estável até 2015. Um novo discurso desenvolvimentista, ao mesmo tempo realçando o compromisso com a geração de emprego e renda e a estabilidade macroeconômica (Pêgo; Campos Neto, 2008), começou a ser anunciado desde o final do primeiro mandato, em 2006, mas seu emblema maior, o Programa de Aceleração do Crescimento (PAC), só foi lançado em 2007.

Objetivou-se, por meio de investimentos principalmente em infraestrutura, aumentar a produtividade das empresas, estimular investimentos privados, gerar emprego e renda e reduzir as desigualdades regionais. Foram priorizados os investimentos (públicos e privados) nos setores de energia, transporte, habitação, saneamento, recursos hídricos, além de programas de impacto social, como o "Minha Casa Minha Vida" (habitação) e o "Luz para Todos" (distribuição de energia elétrica). Em 2010, foi lançado o PAC 2, reafirmando os eixos anteriores (Brasil, 2012).

Os indicadores econômicos e sociais que, a partir de 2004, passaram a apresentar tendências sistematicamente positivas podem ser creditados duplamente ao novo dinamismo econômico e às novas condições políticas, incluindo uma certa reativação das lutas salariais e sindicais. Para Baltar e Krein (2013, p.284), "Foi a primeira vez, desde 1960, que um aumento substantivo da renda do trabalho ocorreu com diminuição do índice de GINI".

Esse novo contexto favoreceu a retomada do crescimento econômico no Nordeste. Tal situação resultou, de um lado, do incremento da capacidade de consumo, favorecido pelo aumento das transferências monetárias federais para a região e em proporção mais elevada do que para as demais regiões, ${ }^{12}$ assim como pela adoção de uma política de valorização do salário mínimo ${ }^{13}$ e pelos reajustes das categorias profissionais acima da inflação. De outro lado, derivou do incre- 
mento nos investimentos públicos e privados. Em balanço sobre os "grandes projetos federais" nos estados nordestinos, para o período 2008 e 2009, Lima e Caldas (2013) indicam como áreas prioritárias: rodovias, ferrovias, portos, aeroportos, saneamento básico e habitação, gasoduto, recuperação e transposição do São Francisco, parques eólicos, hidroelétricas, termelétricas; e concluem que houve uma concentração nas RM de Pernambuco, Bahia e Ceará, entretanto destacando a primeira, em razão dos investimentos no Complexo Industrial Portuário de Suape.

Entre 1999 a 2009, enquanto o Brasil teve o número de empregos formais ampliado em $64,9 \%$, para o Nordeste esse percentual foi de 77,5\% (Lima; Caldas, 2013). Para Déda (2011), de acordo com a PNAD 2009, entre 1992 e 2009 , a renda per capita do Nordeste cresceu $84 \%$ e a do Brasil, $59 \%$.

Mas o Nordeste continuou socialmente diferenciado, ao manter elevados índices de desigualdade e de pobreza. Araújo e Lima (2010) calcularam que, entre 2001 e 2008, a taxa de informalidade ${ }^{14}$ no Nordeste passou de $72,3 \%$ para $66,1 \%$, enquanto no Sudeste, caiu de $43,3 \%$ para $37,1 \%$. Quanto ao rendimento médio mensal do trabalho, entre 2004 e 2008 , a preços de setembro de 2008, passou de R\$ 439 para R\$ 568, no Nordeste, e de R\$ 975 para R\$ 1.123, no Sudeste. Falvo (2013) observa que, apesar dos programas sociais e dos incentivos governamentais, a pobreza continuou marcando a paisagem nordestina.

A partir dos dados da Pesquisa Mensal de Emprego do IBGE, referida a seis RM do país, podemos avaliar melhor, comparativamente, a estrutura ocupacional das de Salvador e Recife (únicas incluídas na base da PME). Na Tabela 1, observa-se que, apesar da queda sistemática nas taxas de desocupação no total das RM, acompanhadas pelas RM de Recife e Salvador, entre fevereiro de 2003 e de 2013, estas últimas se mantiveram sempre em níveis mais elevados do que para o total. ${ }^{15}$ Com as novas dinâmicas dos movimentos migratórios (seja no sentido da intensificação dos fluxos que saem da zona rural e das cidades do interior em direção às grandes cidades, incluindo as regionais - fenômeno particularmente evidenciado nos anos 1990, seja com as migrações de retorno do Sudeste, que também têm como principais destinos as grandes cidades - fenômeno que ganha força nos anos 2000), mesmo com maiores oportunidades de emprego formal nas grandes cidades da região, o trabalho informal ganhou novos impulsos (Fusco, 2012). 
Tabela 1 - Taxa de desocupação por Região Metropolitana (\%) - fevereiro de 2003 a janeiro de 2014

\begin{tabular}{l|c|c|c}
\hline Mês/ano & Total & Recife & Salvador \\
\hline Fev./2003 & 11,6 & 12,1 & 15,0 \\
\hline Fev./2005 & 10,7 & 13,2 & 15,6 \\
\hline Fev./2007 & 9,9 & 12,3 & 13,6 \\
\hline Fev./2009 & 8,5 & 9,1 & 11,0 \\
\hline Fev./2011 & 6,4 & 7,8 & 10,3 \\
\hline Fev./2013 & 5,6 & 6,5 & 6,2 \\
\hline Fev./2014 & 5,1 & 6,4 & 9,0 \\
\hline
\end{tabular}

Fonte: IBGE, Pesquisa Mensal de Emprego.

Quanto à Tabela 2, referida à distribuição da população ocupada por grupos de atividade, de 2003 a 2014, vários aspectos chamam a atenção, entre eles: o peso da indústria caiu para as RM de Recife e Salvador e para o total das RM, mas as primeiras se mantêm bem abaixo desse último; o peso do setor de construção civil cresce sensivelmente na RM de Recife (resultado dos investimentos em Suape e outros); o peso dos serviços prestados a empresas e outros serviços registra importante aumento para as RM de Recife e Salvador (provavelmente, com a intensificação dos processos de terceirização, no que se refere a serviços a empresas, em conformidade com o que sugere Falvo, 2013); o peso dos serviços domésticos cai em todos os casos, embora nas RM nordestinas se mantenha em níveis mais elevados. Como tendência geral, Falvo $(2013$, p.66) indica: “em 2005, o setor terciário empregou cerca de $80,0 \%$ do total de trabalhadores nas RMs de Salvador e de Recife e 70,0\% na RM de Fortaleza, o que mostra o fraco potencial da indústria instalada na criação de postos de trabalho".

Da Tabela 3, voltada à distribuição da população ocupada segundo a posição na ocupação, entre 2005 e 2013, a um crescimento da proporção de "empregados com carteira de trabalho assinada no setor privado" (mais expressivo em Recife e Salvador) corresponderam quedas nos percentuais dos "empregados sem carteira de trabalho assinada no setor privado" e dos "Trabalhadores por conta própria”. Na mesma direção, Falvo (2013, p.65) constatou que o número de empregos formais cresceu significativamente entre 2003 e 2008 nas três RM da região estudadas: "o total de trabalhadores formais detectados pela Relação Anual de Informações Sociais (Rais) aumentou em 27,9\% na RM de Salvador, $34,8 \%$ na RM de Recife, e 35,7\% na RM de Fortaleza, seguindo a tendência nacional e da região do Nordeste de expansão da taxa de formalização”. 
Tabela 2 - Distribuição da população ocupada, por Região Metropolitana, segundo grupamentos de atividade (\%) - fevereiro de 2005 a fevereiro de 2013

\begin{tabular}{l|c|c|c|c}
\hline \multirow{2}{*}{ Grupamentos de atividade } & Mês/ano & $\begin{array}{c}\text { Total Seis } \\
\text { RM }\end{array}$ & Recife & Salvador \\
\hline Indústria extrativa, de transformação e & $2 / 2005$ & 17,5 & 12,2 & 9,6 \\
\cline { 2 - 5 } distribuição de eletricidade, gás e água & $2 / 2013$ & 16,3 & 11,4 & 9,4 \\
\hline Construção & $2 / 2005$ & 7,2 & 5,7 & 8,8 \\
\cline { 2 - 5 } & $2 / 2013$ & 7,6 & 7,8 & 8,5 \\
\hline $\begin{array}{l}\text { Comércio, reparação de veículos } \\
\text { automotores e de objetos pessoais }\end{array}$ & $2 / 2005$ & 19,6 & 25,7 & 21,3 \\
\cline { 2 - 5 } $\begin{array}{l}\text { e domésticos e comércio a varejo de } \\
\text { combustíveis }\end{array}$ & $2 / 2013$ & 18,6 & 24,6 & 20,8 \\
\hline $\begin{array}{l}\text { Serviços prestados a empresa, aluguéis, } \\
\text { atividades imobiliárias e intermediação } \\
\text { financeira }\end{array}$ & $2 / 2005$ & 15,1 & 12,7 & 13,6 \\
\cline { 2 - 5 } & $2 / 2013$ & 16,2 & 15,7 & 16,7 \\
\hline $\begin{array}{l}\text { Educação, saúde, serviços sociais, } \\
\text { administração pública, defesa e seguridade } \\
\text { social }\end{array}$ & $2 / 2005$ & 15,8 & 19,2 & 17,6 \\
\cline { 2 - 5 } & $2 / 2013$ & 16,4 & 17,7 & 18,1 \\
\hline Serviços domésticos & $2 / 2005$ & 7,7 & 8,4 & 8,8 \\
\cline { 2 - 5 } & $2 / 2013$ & 6,0 & 6,7 & 7,3 \\
\hline $\begin{array}{l}\text { Outros serviços (alojamento, transporte, } \\
\text { limpeza urbana e serviços pessoais) }\end{array}$ & $2 / 2005$ & 17,4 & 16,5 & 18,2 \\
\cline { 2 - 5 } & $2 / 2013$ & 18,4 & 15,6 & 18,2 \\
\hline
\end{tabular}

Fonte: IBGE, Pesquisa Mensal de Emprego.

Tabela 3 - Distribuição da população ocupada, por Região Metropolitana, segundo a posição na ocupação (\%) - fevereiro de 2005 e a fevereiro de 2013

\begin{tabular}{l|c|c|c|c}
\hline Posição na ocupação & Mês/ano & $\begin{array}{c}\text { Total Seis } \\
\text { RM }\end{array}$ & Recife & Salvador \\
\hline Empregados com carteira de trabalho & $2 / 2005$ & 40,4 & 35,0 & 37,0 \\
\cline { 2 - 5 } assinada no setor privado & $2 / 2013$ & 50,0 & 47,1 & 47,1 \\
\hline \multirow{2}{*}{$\begin{array}{l}\text { Empregados sem carteira de trabalho } \\
\text { assinada no setor privado }\end{array}$} & $2 / 2005$ & 15,7 & 15,1 & 13,8 \\
\cline { 2 - 5 } & $2 / 2013$ & 10,1 & 10,0 & 10,7 \\
\hline \multirow{2}{*}{ Militares e funcionários públicos } & $2 / 2005$ & 7,2 & 9,4 & 7,5 \\
\cline { 2 - 5 } & $2 / 2013$ & 7,5 & 8,9 & 7,7 \\
\hline \multirow{2}{*}{ Trabalhadores por conta própria } & $2 / 2005$ & 19,4 & 22,4 & 22,5 \\
\cline { 2 - 5 } & $2 / 2013$ & 17,9 & 19,0 & 19,9 \\
\hline \multirow{2}{*}{ Empregadores } & $2 / 2005$ & 5,3 & 4,5 & 4,1 \\
\cline { 2 - 5 } & $2 / 2013$ & 4,6 & 4,3 & 3,5 \\
\hline
\end{tabular}

Fonte: IBGE, Pesquisa Mensal de Emprego. 
Quanto à Tabela 4, sobre a evolução do rendimento médio real habitual da população ocupada, por Região Metropolitana, entre 2005 e 2013, ficam evidentes, de um lado, o crescimento generalizado nos rendimentos médios da população ocupada, mas, de outro, a permanência das RM de Recife e Salvador em patamares inferiores ao do total das RM do país.

Tabela 4 - Evolução do rendimento médio real habitual da população ocupada, por Região Metropolitana (a preços de fevereiro de 2013) - fevereiro de 2003 a fevereiro de 2013

\begin{tabular}{l|c|c|c}
\hline Mês/ano & Total & Recife & Salvador \\
\hline Fev./2003 & $1.555,33$ & $1.057,25$ & $1.181,25$ \\
\hline Fev./2005 & $1.432,05$ & 998,01 & $1.076,08$ \\
\hline Fev./2007 & $1.541,79$ & $1.096,65$ & $1.193,94$ \\
\hline Fev./2009 & $1.652,96$ & $1.084,40$ & $1.293,56$ \\
\hline Fev./2011 & $1.729,15$ & $1.200,26$ & $1.349,25$ \\
\hline Fev./2013 & $1.849,50$ & $1.376,00$ & $1.443,60$ \\
\hline
\end{tabular}

Fonte: IBGE, Pesquisa Mensal de Emprego.

O Complexo Industrial Portuário de Suape, tratado aqui como o emblema do novo momento do desenvolvimento regional, está situado na RM de Recife, Litoral Sul de Pernambuco, nos municípios de Ipojuca e Cabo de Santo Agostinho, abrangendo uma área de 13,4 mil hectares. A partir da primeira edição do PAC, em 2007, se constituiu em um dos maiores polos de investimentos do país.

Pernambuco passou a viver um boom econômico, após um período de declínio. De 1963 a 1969, o estado foi o principal beneficiário dos recursos da Sudene, recebendo 36,9\% destes (seguido da Bahia, com 32,8\%). Nos períodos subsequentes, no entanto, essa participação foi decrescente, sendo de $25,7 \%$, de 1970 a 1974, e de 16,6\%, de 1975 a 1984 . O PIB estadual cresceu 10,6\% ao ano, de 1970 a $1975,6,6 \%$, de 1975 a 1980, e 2,4\%, de 1980 a 1985, invertendo sua relação com o PIB regional (com médias anuais, respectivamente, de $10,2 \%, 7,2 \%$ e 4,4\%). Após alguma recuperação no final dos anos 1980, o PIB estadual cresceu, na década de 1990, com médias anuais de 2,0\%, e o Nordeste, com 3,0\% (Lima; Katz, 1993).

A proposta do Porto de Suape surgiu nos anos 1960, mas a criação da empresa pública estadual foi formalizada apenas em 1978 e o seu funcionamento, iniciado em 1986 (Pernambuco, 2010). Na avaliação de Santos (2012), até 2005, os investimentos em Suape não foram além de empreendimentos de médio porte. $\mathrm{O}$ anúncio do projeto da Refinaria Abreu e Lima demarcou um outro momento na sua trajetória. 
A partir de 2007, com o PAC, o Complexo passou a atrair grandes investimentos públicos e privados, convertendo-se, com seu entorno, em um gigantesco "canteiro de obras". Os investimentos públicos em Suape passaram de R\$ 155 milhões (entre 1995 e 1998), para R 136 milhões (1999 a 2002) e para R\$ 147,6 milhões (2003 a 2006); enquanto, entre 2007 e 2010, pularam para R \$ 1,46 bilhões. Quanto às inversões privadas, totalizaram US\$ 2,2 bilhões até 2006; e, de 2007 a 2010, reuniram US\$ 17 bilhões (Pernambuco, 2010).

O Complexo chegou, no final da década de 2000, com mais de $100 \mathrm{em}-$ presas instaladas e dezenas de outras em fase de instalação. Alguns destaques: Refinaria Abreu e Lima e Petroquímica Suape (Petrobras); Estaleiro Atlântico Sul (EAS); Energética Suape (termelétrica); Impsa Wind Power (fabricação de geradores eólicos); Bunge (refinaria de óleos vegetais, fabricação de margarinas e moinho de trigo); Tecon Suape (logística do porto) (Pernambuco, 2010). A Refinaria representou o maior investimento, chegando a envolver na sua construção cerca de 50 mil no final de 2012 (Santos, 2012).

Para Moutinho et al. (2011), o bom momento da economia pernambucana sobretudo resultou de definições estratégicas de desenvolvimento nacional e regional, materializadas nos grandes investimentos do PAC, nos quais se destacaram, além de Suape: a Ferrovia Nova Transnordestina, a Transposição do Rio São Francisco, o Polo Farmacoquímico. Acrescente-se a esses: a fábrica da Fiat, a Cidade da Copa, entre outros. Com isso, o projeto Suape adquiriu peso nas agendas do governo do estado e dos governos municipais do entorno, ganhou uma posição de destaque na mídia local e no imaginário dos pernambucanos.

Entre 2005 e 2012, o PIB de Pernambuco teve como taxas anuais: $4,2 \%$, $5,1 \%, 5,4 \%, 5,3 \%, 5,2 \%, 9,3 \%, 4,5 \%$ e $2,3 \%$ (Instituto Brasileiro de Geografia e Estatística, 2005-2012). Em 2003, Ipojuca já detinha o quarto maior PIB de Pernambuco $(5,9 \%)$, com Cabo em terceiro $(6,2 \%)$, Jaboatão em segundo $(8,5 \%)$ e Recife em primeiro (33,3\%). Em 2005, o PIB per capita de Ipojuca se tornou o maior do estado, representando mais de 4,6 vezes o da cidade de Recife. Em 2007, o PIB de Ipojuca passou a terceiro, invertendo sua posição com Cabo. Em 2010, chega ao segundo lugar (com 9,6\% do PIB estadual), alcançando um PIB per capita de 5,8 vezes o da capital (Instituto Brasileiro de Geografia e Estatística, 2003-2010). O crescimento populacional em Cabo e Ipojuca também teve evolução expressiva, sendo de $21,0 \%$ e $36,0 \%$, respectivamente, enquanto o Nordeste cresceu 11,1\% e Pernambuco, 10,9\%, no mesmo período (Instituto Brasileiro de Geografia e Estatística, 2000-2010).

A problemática social, entretanto, persistiu. Para Ipojuca, em 2010, o valor do rendimento nominal mediano mensal das pessoas de 10 anos ou mais de idade, com rendimento economicamente ativas ficou em R\$530,00 e, para Cabo, em R \$ 600,00, enquanto para Recife e São Paulo esse valor atingiu R 700,00 e R\$ 1.020,00, respectivamente (Instituto Brasileiro de Geografia e Estatística, 2010). Em Ipojuca, a taxa de analfabetismo, embora tenha caído, entre 2000 e 
2010 , de $28,7 \%$ para 19,2\%, manteve-se acima das verificadas para Pernambuco, 18,0\%, Nordeste, 19,1\%, e Brasil, 9,6\% (Instituto Brasileiro de Geografia e Estatística, 2000 e 2010). Uma já comprometida infraestrutura urbana e de serviços passou a sofrer uma forte pressão com o extraordinário fluxo migratório para a região (Monteiro, 2011).

As críticas às consequências ambientais e sociais do projeto estiveram presentes desde as suas origens. ${ }^{16}$ Mas o empreendimento seguiu e ganhou maior legitimidade e força quando da retomada de uma agenda desenvolvimentista no país e na região. Estabeleceu-se incorporando elementos da crítica, em um esforço de justificação (Boltanski; Chiapello, 2009). Foi assim que o novo Plano Diretor Suape 2030, publicado em 2011, buscou compatibilizar suas razões econômicas com demandas ambientais, culturais e sociais. $\mathrm{O}$ adjetivo "sustentável" ganhou importância crescente nos discursos dos agentes estratégicos de Suape, especialmente a partir do Programa Suape Sustentável, lançado em 2011 , envolvendo os gestores do Complexo, secretarias de estado, prefeituras, as empresas instaladas em Suape, o BNDES, o Banco do Nordeste etc. Declarou-se, com o referido Programa, o propósito de transformar Suape e seu Território Estratégico em um modelo de "desenvolvimento sustentável", "equilibrando o crescimento econômico, a inclusão social e a preservação do meio ambiente" (Pernambuco, 2012).

Sobre o tema do trabalho, começava a ganhar evidência no país a questão da qualificação profissional. Órgãos de mídia, em tom sensacionalista, passaram a falar de "apagão de mão de obra”. No que se refere a Suape, estudo de Moutinho et al. (2011), diante da crescente carência de trabalhadores qualificados para os diversos novos segmentos produtivos em Suape, evidenciou o desafio de converter trabalhadores com baixa escolaridade em operários qualificados. Também Monteiro (2011) comentou que as elevadas exigências de qualificação profissional contrastavam com o perfil da mão de obra disponível na região.

Nesse mesmo momento, a eclosão de uma onda de conflitos, protagonizada pelos operários dos canteiros de obra de Suape, realçou outros aspectos dessa nova dinâmica socioeconômica. Especialmente a partir de 2011, revoltas, paralisações e greves, acompanhadas por confusos e tensos processos de negociação social e sindical, envolvendo os próprios operários, sindicatos, empresas, governos estadual e municipais, Ministério Público do Trabalho (MPT), Ministério do Trabalho e Emprego, Justiça do Trabalho, órgãos de mídia, entre outros, marcaram fortemente a cena da região (Véras de Oliveira, 2013a).

Apesar dos ganhos imediatos trazidos com as referidas mobilizações, o quadro das condições de trabalho não foi decisivamente modificado. Ao contrário, com a crise que se estabeleceu na economia brasileira, a partir de 2015, com fortes impactos no Nordeste, em Pernambuco e Suape, abriu-se um novo ciclo de perdas para os trabalhadores da região cujo alcance ainda está claramente delimitado. Inaugura-se uma nova fase, sem que se apresentem sinais claros dos novos rumos. 


\section{Considerações finais}

Em reportagem do jornal Folha de S.Paulo, de 6 de março deste ano de 2016 (http://wwwl.folha.uol.com.br/mercado/2016/03/17469l4-norte-e-nordeste-perdem-folego-e-viram-lanterna-da-economia.shtml), com base no Índice de Atividade Econômica Regional do Banco Central, evidencia-se que em um cenário de recessão generalizada o Norte e o Nordeste se encontram em pior situação. Entre 2014 e 2015, as respectivas regiões passaram de um crescimento em torno de $2 \%$ para uma retração na casa dos $3 \%$, quando para o mesmo período o Sudeste registrou retração de 2,5\%. A reportagem ainda considera que a Operação Lava Jato da Polícia Federal, que investiga denúncias de corrupção na Petrobras, têm afetado Suape, com a paralização das obras da Refinaria Abreu e Lima e a suspensão de encomendas de navios aos estaleiros da região.

Retomando os dados da PME/IBGE, enquanto a taxa de desocupação do conjunto das seis RM pesquisadas passou de 5,1\%, em fevereiro de 2014, para $8,2 \%$, em fevereiro de 2016, nos casos das RM de Recife e Salvador tais indicadores registraram níveis bem mais elevados, para os mesmos períodos, com variações de $6,4 \%$ para $10,4 \%$ e de $9,0 \%$ para $12,6 \%$, respectivamente. Quanto ao "Rendimento médio real habitual da população ocupada, por região metropolitana (a preços de fevereiro de 2016)", as variações para o período acima referido, considerando-se o conjunto das seis RM, foram de R $2.420,05$ para $\mathrm{R} \$ 2.227,50$, respectivamente, enquanto para as RM de Recife e Salvador tais indicadores variaram de $\mathrm{R} \$ 1.773,12$ para $\mathrm{R} \$ 1.647,80$ e de $\mathrm{R} \$ 1.851,67$ para R\$ 1.653,60. Do ponto de vista dos "Indicadores de distribuição da população ocupada", nas referidas RM e para os períodos aqui considerados, ao lado do crescimento dos níveis de desocupação e da queda dos rendimentos aparecem outros sinais de deterioração do mercado de trabalho, tais como a queda no percentual de "empregados com carteira assinada no setor privado" e aumento da proporção dos "trabalhadores por conta própria". Para o conjunto das seis RM, no primeiro caso, o percentual oscila de $51,0 \%$ para $50,7 \%$, enquanto para a RMR vai de $47,2 \%$ para $45,8 \% \%$, e para a RMS vai de $46,9 \%$ para $46,1 \%$. No segundo caso, no conjunto das RM, passa de $18,7 \%$ para $29,0 \%$, enquanto para a RMR cresce de $20,4 \%$ para $22,9 \%$, e para a RMS cresce de $21,1 \%$ para $25,1 \%$. Em todos os aspectos os sinais de deterioração são mais acentuados nas duas RM situadas no Nordeste, em comparação com o quadro nacional.

Considere-se que, observando o cenário que se apresenta, a tendência é de piora desses indicadores. Com a posse do governo interino, em razão da suspensão do mandato de Dilma em maio deste ano em cumprimento aos rituais do processo de impeachment a ser julgado pelo Senado, as medidas que vêm sendo anunciadas nas áreas econômica e social, em geral fundamentadas no documento "Ponte para o Futuro", lançado pelo PMDB em fins de 2015, apontam para as seguintes prioridades: aprofundar o ajuste fiscal, na base de cortes de gastos (principalmente sociais e nos investimentos públicos) e eventual aumento de 
tributos, de modo a priorizar os serviços da dívida pública; diminuir o tamanho do Estado e avançar em uma agenda radical de privatizações; atender demandas corporativas dos segmentos que constituem a base de apoio político (esta última em flagrante contradição com o discurso da austeridade fiscal).

$\mathrm{Na}$ área social, entre os alvos prioritários do governo interino estão os direitos sociais inscritos na Constituição de 1988, os direitos trabalhistas previstos na Consolidação das Leis do Trabalho (CLT) e os programas sociais implementados pelos governos do PT. Uma das medidas mais contundentes se refere à desvinculação orçamentária dos recursos destinados pela Constituição de 1988 para a Saúde e a Educação. Em outra frente, almeja-se o fim da Política de valorização do Salário Mínimo, nascido em 2004 de um acordo entre o governo e as centrais sindicais. No item legislação trabalhista, a palavra de ordem é "flexibilização". As principais mudanças tramitam na forma de projetos de lei (PL). São destaques: a liberalização da terceirização em toda a economia, minando os efeitos protetivos da CLT (já aprovado na Câmara dos Deputados, o PL encontra-se tramitando no Senado); a prevalência das negociações coletivas (convenções ou acordos) sobre as garantias legais; a redução da idade para início da atividade laboral de 16 para 14 anos; negociações diretas entre trabalhadores e empregadores, sem a intermediação dos sindicatos; a redução da jornada de trabalho com redução de salários; a alteração da definição de "trabalho escravo", não mais considerando nessa categoria jornada exaustiva e trabalho degradante. O retrocesso social que se anuncia provavelmente terá no Nordeste um dos seus impactos mais contundentes.

\section{Notas}

1 Este texto foi originalmente publicado sob o título "Desenvolvimento e trabalho no Nordeste: velha nova problemática”, em: Nascimento, A.; Lima, M. C. (Org.) O Nordeste brasileiro em questão: uma agenda para reflexão. Recife: Editora Universitária da UFPE, 2014. A presente versão sofreu modificações.

2 Ver estudo recente de Ramalho e Véras de Oliveira (2013a).

3 Oliveira (2003, p.41) destaca, sobre a expansão capitalista no Brasil, comandada por São Paulo a partir dos anos 1930, que ao Nordeste coube a condição de reservatório de mão de obra, dando início aos fluxos migratórios para o Centro-Sul.

4 Para autores como Gomes e Vergolino (1995), ao contrário, os polos conseguiram gerar efeitos diversificadores, complexificando sua constituição e multiplicando, assim, suas influências, não se justificando que sejam tratados como "enclaves".

5 Ver a respeito, por exemplo, Véras de Oliveira (2011a).

6 Agier, Guimarães e Castro (1995, p.53) ressaltam, também em estudo sobre o Complexo: "mediante seu autoritarismo e despotismo, a política fabril exibe em cores fortes o desprezo culturalmente reservado para o trabalho pesado ou subordinado".

7 Ver, por exemplo, Véras de Oliveira (2011b e 2013b). 
8 Uma década depois, o Sebrae (2013) estimou em mais de 18 mil o número de unidades produtivas no aglomerado.

9 No cálculo de Saboia (2001), com base nos dados da Rais, entre 1989 e 1998, houve uma queda de 35,3\% no nível de emprego formal no Sudeste, de 19,4\% no Nordeste, sendo de $41,5 \%$ em Pernambuco, de 25,3\% na Bahia, e de 15,4\% no Maranhão, enquanto o Ceará teve um incremento positivo de 15,1\%. Para Araújo, Souza e Lima (1997), entre 1990 e 1995 , enquanto a Bahia teve um crescimento médio anual de 2,2\%, Pernambuco, de 1,5\%, o Maranhão, de 2,9\%, o Nordeste, 2,6\% e o Brasil, de $2,7 \%$, a taxa do Ceará, para o mesmo período, foi de $5,3 \%$.

10 Ver, por exemplo, Dulci (2002).

11 Após amargar taxas médias de crescimento de $1,57 \%$ e de 2,50\%, respectivamente, entre 1981-1990 e 1991-2000, o Produto Interno Bruto do Brasil variou em 3,61\%, entre 2001-2010, e em 2004 foi de 5,70\%; em 2005, de 3,20\%; em 2006, de 4,00\%; em 2007, de 6,10\%; em 2008, de 5,20\%; em 2009, de -0,30\%; e em 2010, de 7,50\%. Em 2011, 2012 e 2013, no entanto, se mantiveram em patamares abaixo dessa média: de $2,70 \%, 0,9 \%$ e $2,57 \%$ (estimativa), respectivamente (Banco Central do Brasil - https://www.bcb.gov.br/?Indeco).

12 Para Falvo (2013), baseando-se em dados do Governo Federal para os anos 2006 a 2008, o valor dos benefícios do Programa Bolsa Família destinados ao Nordeste ficou acima de $50 \%$ do total, sendo de quase $50 \%$ no caso da Previdência Social Rural e de $35 \%$ quanto ao Benefício de Prestação Continuada.

13 Em relação à valorização do salário mínimo em 32\%, entre abril de 2002 e de 2007, Falvo (2013, p.54) comenta: “A contribuição relativa dessa valorização foi maior para os trabalhadores nordestinos do que para os brasileiros em geral, tendo em vista que $14 \%$ daqueles e $10 \%$ desses recebiam exatamente o salário mínimo em 2007. Não podemos esquecer que o salário mínimo é a base dos benefícios da previdência e do PBF com larga cobertura na população nordestina".

14 Tomando-se como critério a proporção da força de trabalho que não contribui para a Previdência Social.

15 Referindo-se aos dados da Pesquisa de Emprego e Desemprego da Fundação Seade - PED/Seade/Dieese, Falvo (2013, p.62) realça essas duas tendências: "grande queda das taxas de desemprego nas RMs de Salvador e Recife na década de 2000", mas "essas foram as duas maiores taxas de desemprego dentre as metrópoles cobertas pela pesquisa".

16 Ver, por exemplo, o "Manifesto Suape" foi publicado, sob a liderança do economista Clóvis Cavalcanti, no semanário Jornal da Cidade, Recife, n. 24, a. 2, p. 6-12, 12 abr. 1975. Disponível em: <http://cloviscavalcanti.blogspot.com.br/p/manifesto-suape. html>. Acesso em: 25 jun. 2012.

\section{Referências}

AGIER, M.; GUIMARÃES, A. S.; CASTRO, N. A. (Org.) Imagens e identidades do trabalho. São Paulo: Hucitec; Paris: Orstrom, 1995. 
ALMEIDA, P. H. de. A economia de Salvador e a formação de sua Região Metropolitana. In: CARVAlHO, I. M. M. de; PEREIRA, G. C. (Org.) Como anda Salvador e sua região metropolitana. Salvador: Edufba, 2008.

ANTUNES, R. Trabalho, reestruturação produtiva e algumas repercussões no sindicalismo brasileiro. In: (Org.) Neoliberalismo, trabalho e sindicatos: reestruturação no Brasil e na Inglaterra. São Paulo: Boitempo Editorial, 1997.

ARAÚJO, N. G. de. A industrialização no Ceará: breves considerações. Boletim Goiano de Geografia, Goiana, v.27, n.2, jan./jun. 2007.

ARAÚJO, T. B. Nordeste, Nordestes: que Nordeste? - Versão Revisada. Observanordeste, 2002 Disponível em: <http://www.fundaj.gov.br/index.php?option=com_content\&v iew $=$ article $\& i d=1956 \% 3$ Anordeste-nordestes-que-nordeste- $\&$ catid $=58 \& I$ temid $=414$. Acesso em: 15 jan. de 2013.

ARAÚJO, T. P.; LIMA, R. A. de. Aspectos estruturais do mercado de trabalho em contexto recente da economia brasileira: contraponto Nordeste-Sudeste. In: MORETTO, A. et al. (Org.) Economia, desenvolvimento regional e mercado de trabalho do Brasil. Fortaleza: IDT/BNB; Campinas: Cesit/Unicamp, 2010.

ARAÚJO, T. P. de; SOUZA, A. do V.; LIMA, R. A. de. Nordeste: economia e mercado de trabalho. Estudos Avançados, São Paulo, v.11, n.29, jan./abr. 1997.

BALTAR, P. E. de A.; KREIN, D. A retomada do desenvolvimento e a regulação do mercado do trabalho no Brasil. Caderno CRH, Salvador, v.26, n.68, maio/ago. 2013.

BATISTA JÚNiOR, P. N. Desenvolvimento “light”? Folha de S.Paulo, São Paulo, 25 jan. 2007.

BOLTANSKI, L.; CHIAPELlO, E. O novo capitalismo. São Paulo: WMF Martins Fontes, 2009.

BRASIL. Programa de Aceleração do Crescimento: balanço 4 anos (2007-2010). Brasília, DF: Ministério do Planejamento, 2010.

PAC 2. Brasília, DF: Ministério do Planejamento, 2012.

CARVALHO, I.; HAGUETTE, T. (Org.) Trabalho e condições de vida no Nordeste brasileiro. São Paulo: Hucite; Brasília, DF: CNPq, 1984.

CASTRO, N. A.; GUIMARÃES, A. S. Classe proletária, trabalhadores prósperos. In: GUIMARÃES, A. S; AGIER, M.; CASTRO, N. A. (Org.) Imagens e identidades do trabalho. São Paulo: Hucitec; Paris: Orstrom, 1995, p.19-37.

CASTRO, N.; LEITE, M. A sociologia do trabalho industrial no Brasil: desafios e interpretações. BIB, Rio de Janeiro, n.37, $1^{\circ}$ sem. 1994.

CAVALCANTI, C. Cientistas lançam manifesto contra o complexo de suape. Jornal da Cidade, Recife, n.24, a.2, 6 dez. 1975.

DANTAS, E.; SILVA, J. B. da. A formação histórica da metrópole e as principais tendências de desenvolvimento. In: PEQUENO, L. (Org.) Como anda Fortaleza. Rio de Janeiro: Letra Capital - Observatório das Metrópoles, 2009. v.5.

DÉDA, M. O que quer o Nordeste. O Globo, Rio de Janeiro, 22 fev. 2011 Disponível em: <http://www.ipea.gov.br/portal/index.php?option=com_content\&view=article \&id=7380\&Itemid=75>. Acesso em: 10 mar. 2014. 
DRUCK, M. da G. Terceirização: (des)fordizando a fábrica: um estudo do complexo petroquímico. Salvador: Edufba; São Paulo: Boitempo, 1999.

DULCI, O. S. Guerra fiscal, desenvolvimento desigual e relações federativas no Brasil. Revista de Sociologia e Politica, Curitiba, n.18, jun. 2002.

FALVO, J. F. A desigualdade social nas metrópoles de Salvador, Recife e Fortaleza. In: CASTRO, I. S. B. (Org.) Novas interpretações desenvolvimentistas. Rio de Janeiro: Centro Internacional Celso Furtado, 2013.

FALVO, J. F.; SIQUEIRA, H. As interações entre a dimensão urbano-regional e a estrutura de ocupações nas metrópoles do Nordeste brasileiro. Revista da ABET, São Paulo, v.7, n.2, jul./dez. 2008.

FUSCO, W. Regiões metropolitanas do Nordeste: origens, destinos e retornos de migrantes. Revista Interdisciplinar de Mobilidade Urbana, Brasília, a.20, n.39, jul./dez. 2012.

GOMES, G. M.; VERGOLINO, J. R. A macroeconomia do desenvolvimento nordestino: 1960/1994. Brasília, DF: Ipea, 1995. (Texto para Discussão, n.372).

GRUPO DE TRABALHO PARA O DESENVOLVIMENTO DO NORDESTE. Uma politica de desenvolvimento econômico para o Nordeste. Recife: Sudene, 1967.

GUIMARÃES NETO, L. Trajetória econômica de uma região periférica. Estudos Avançados, São Paulo, v.11, n.29, jan./abr. 1997.

HARVEY, D. Condição pós-moderna. São Paulo: Edições Loyola, 1992.

INSTITUTO BRASILEIRO DE GEOGRAFIA E ESTATÍSTICA. Censo. Brasília, DF, 2000-2010.

Pesquisa Mensal de Emprego. Brasília, DF, 2013.

LIMA, J. As artimanhas da flexibilização: o trabalho terceirizado em cooperativas de produção. São Paulo: Terceira Margem, 2002.

LIMA, P. Economia do Nordeste: tendências recentes das áreas dinâmicas. Revista Análise Econômica, Porto Alegre, a.12, n.21-22, mar./set. 1994.

LIMA, P.; CALDAS, R. de M. Investimento em infraestrutura, distribuição de renda e desenvolvimento: experiências recentes e os desafios do Nordeste. In: CASTRO, I. S. B. (Org.) Novas interpretações desenvolvimentistas. Rio de Janeiro: Centro Internacional Celso Furtado, 2013. p.99-142.

LIMA, P.; KATZ, F. A economia de Pernambuco: perda de dinamismo e a necessidade de buscar caminhos possíveis. Cadernos de Estudos Sociais, Recife, v.9, n.1, jan./jun. 1993.

LIPIETZ, A. Miragens e milagres: problemas de industrialização no Terceiro Mundo. São Paulo: Nobel, 1988.

MONTEIRO, A. L. R. Refinaria Abren e Lima em Suape: perspectivas para o desenvolvimento econômico regional. Recife, 2011. Tese (Doutorado em Geografia) - Programa de Pós-Graduação em Geografia, Universidade Federal de Pernambuco. Recife, 2011 .

MOUTINHO, L. M. G. et al. Impactos dos grandes projetos federais na economia de Pernambuco e proposições de políticas. In: Análise do mapeamento e das políticas para Arranjos Produtivos Locais no Norte, Nordeste e Mato Grosso e dos impactos dos grandes 
projetos federais no Nordeste. Rio de Janeiro: BNDES, 2011. (Nota Técnica, 13). p.163182.

OLIVEIRA, F. de. Elegia para uma Re(li)gião: Sudene, Nordeste, planejamento e conflito de classes. 3.ed. Rio de Janeiro: Paz e Terra, 1981.

O elo perdido: classe e identidade de classe na Bahia. São Paulo: Fundação Perseu Abramo, 2003a.

Crítica à razão dualista: o ornitorrinco. São Paulo: Boitempo, 2003 b.

OLIVEIRA, F. M. de. Trabalho em turismo e suas diferenças regionais no Brasil. In: MORETTO, A.; KREIN, D.; POCHMANN, M.; MACAMBIRA JÚNIOR. (Org.) Economia, desenvolvimento regional e mercado de trabalho do Brasil. Fortaleza: IDT/ BNB; Campinas: Cesit/Unicamp, 2010. p.105-38.

PÊGO, B.; CAMPOS NETO, C. A. da S. O PAC e o setor elétrico: desafios para o abastecimento do mercado brasileiro (2007-2010). Brasília, DF: IPEA, 2008. (Texto para Discussão, n.1329).

PERNAMBUCO. Complexo Industrial de Suape. PAC/Complexo Suape: Relatório mar. 2010. Disponível em:< http://www.suape.pe.gov.br/pdf/relatorioObraSuapeMarco2010.pdf>. Acesso em: 22 jun. 2012.

Suape sustentável. Disponível em: <https://www.suape.pe.gov.br/news/matLer.php?id=111>. Acesso em: 25 jan. 2013.

POCHMANN, M. O emprego no desenvolvimento da nação. São Paulo: Boitempo, 2008.

QUADROS, W. A evolução da estrutura social brasileira: notas metodológicas. Campinas: IE/Unicamp, 2008. (Texto para Discussão, n.147). Disponível em: http://www. eco.unicamp.br/docdownload/publicacoes/textosdiscussao/textol47.pdf>. Acesso em: 5 mar. 2014.

RAMAlHO, J. R.; VÉRAS DE OLIVEIRA, R. (Org.) Dossiê: Trabalho e desenvolvimento - um debate atual? Caderno CRH, Salvador, v.26, 2013a.

A atualidade do debate sobre trabalho e desenvolvimento - introdução. Caderno CRH, Salvador, v.26, $2013 \mathrm{~b}$.

RAPOSO, M.; GOMES, G. Estudo de caracterização econômica do Polo de Confecções do Agreste de Pernambuco. Recife: Fade; UFPE; Sebrae, 2003. Disponível em: <http://200.249.132.89:8030/downloads/poloconfec.pdf>. Acesso em: 10 fev. de 2010.

REVISTA EXAME. A corrida da qualificação. Edição 965.7 de abril de 2010.

ROCHA, D. A dialética do local e do global: os atores e as metamorfoses dos lugares no litoral do cabo de Santo Agostinho. Recife, 2000. Dissertação (Mestrado em Geografia) - Programa de Pós-graduação em Geografia, Universidade Federal de Pernambuco. Recife, 2000.

SABOIA, J. A dinâmica da descentralização industrial no Brasil. Rio de Janeiro: UFRJ; IE, 2001. (Texto para Discussão, n.452).

SANTOS, V. M. dos. Entrevista. IHU On-Line, 24 abr. 2012. Acesso em: <www.ihu. unisinos.br/entrevistas/508579-suape-um-desafio-para-pernambuco-entrevista-especial-com-valdeci-monteiro-dos-santos>. Acesso em: 10 jan. 2013. 
SINGER, P. A economia urbana de um ponto de vista estrutural. In: SOUZA, G. A. de; FARIA, V. (Org.) Bahia de todos os pobres. Petrópolis: Vozes; Cebrap, 1980.

TOLEDO, E. de la G. (1997), "La flexibilidad del trabajo en América Latina”, Revista Latino Americana de Estudios del Trabajo, São Paulo, ano 3, n.5, 1997.

VÉRAS DE OLIVEIRA, R. Sindicalismo e democracia no Brasil: do novo sindicalismo ao sindicato cidadão. São Paulo: Annablume, 2011 a.

O Polo de Confecções do Agreste de Pernambuco: ensaiando uma perspectiva de abordagem. In: ARAÚJO, Â.; VÉRAS DE OLIVEIRA, R. (Org.) Formas de trabatho no capitalismo atual. São Paulo: Annablume, 2011 b.

Suape em construção, peões em luta: o novo desenvolvimento e os conflitos do trabalho. Caderno CRH, Salvador, v.26, p.233-52, $2013 \mathrm{a}$.

O Polo de Confecções do Agreste de Pernambuco: elementos para uma visão panorâmica. In: VÉRAS DE OLIVEIRA, R.; SANTANA, M. A. (Org.) Trabalho em territórios produtivos reconfigurados no Brasil. João Pessoa: Editora Universitária da UFPB, 2013b.

RESUMO - Este ensaio tem como propósito identificar e analisar, em perspectiva histórica, as dinâmicas sociais do trabalho que se estabeleceram no Nordeste, especialmente a partir da reconfiguração socioeconômica da região empreendida com a criação da Superintendência do Desenvolvimento do Nordeste (Sudene), no final dos anos 1950. Motivado pela retomada na última década de uma agenda de grandes projetos público-privados no país e na região, busca-se sob um olhar retrospectivo contribuir para adensar o entendimento do momento atual e de suas possibilidades de desdobramentos, no que tange aos temas dos padrões de desenvolvimento e das correspondentes relações de trabalho.

PALAVRAS-CHAVE: Padrões de desenvolvimento, Relações de trabalho, Nordeste.

ABSTRACT - This paper aims to identify and analyze, from a historical perspective, the social dynamics of labor that have been established in Northeastern Brazil, taking into account especially the socioeconomic reconfiguration brought by the creation of the Superintendence for the Development of the Northeast (Sudene) in the late 1950s. The article is motivated by the resumption, over the last decade, of an agenda of large public-private projects in the country and in the region. We seek here, from a retrospective 
viewpoint, to improve the understanding of the current situation and its possibilities and tendencies regarding development patterns and the corresponding labor relations. KEYWORDS: Development patterns, Labor relations, Northeastern Brazil.

Roberto Véras de Oliveira é doutor em Sociologia pela Universidade de São Paulo. Professor do Departamento de Ciências Sociais e do Programa de Pós-Graduação em Sociologia da Universidade Federal da Paraíba. Professor do Programa de Pós-Graduação em Ciências Sociais da Universidade Federal de Campina Grande.

@ - roberto.veras.2002@gmail.com

Recebido em $1^{0} .7 .2016$ e aceito em 18.7.2016.

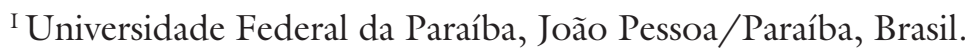


